\title{
KEBERADAAN KEBIASAAN NGINANG PADA MASYARAKAT MELAYU DI KECAMATAN SEBERANG ULU I KOTA PALEMBANG
}

\author{
Suryo Arief Wibowo ${ }^{1}$, Endang Rochmiatun ${ }^{2}$, Amilda $^{3}$ \\ Fakultas Adab dan Humaniora. UIN Raden Fatah Palembang \\ email: suryoarief31@gmail.com
}

\begin{abstract}
Abstrak
Kemajuan zaman serta mudahnya budaya asing masuk dalam kehidupan generasi sekarang membuat banyak kearifan lokal mulai mengalami degradasi hingga dapat mengalami kepunahan. Seperti halnya, generasi muda yang keturunan Melayu Palembang, pada saat ini sudah meninggalkan tradisi yang sudah diwariskan turun temurun yaitu tradisi nginang. Nginang merupakan kebiasaan yang sudah menjadi tradisi temurun yang dilakukan masyarakat Melayu di Sumatera serta di Palembang. Dalam penelitian ini bertujuan untuk mengungkap fenomena kebiasaan nginang yang masih dilakukan oleh sebagian masyarakat Melayu di Palembang. Penelitian ini menggunakan jenis penelitian deskriptif-kualitatif dengan menggunakan metode etnografi yang merupakan pendekatan disiplin ilmu antropologi. Sumber data yang digunakan adalah sumber data primer dan sumber sekunder. Sumber primer yang berasal dari orang yang nginang dan budayawan. Sumber sekunder berasal dari laporan penelitian, buku, arsip, dan sebagainya. Teknik Pengumpulan data menggunakan observasi secara langsung ke lokasi yaitu di Kecamatan Seberang Ulu I Kota Palembang. Adapun menggunakan wawancara partisipan yaitu informan kunci sebagai data utama dan menggunakan studi pustaka yang relevan dalam mendukung penelitian ini serta mengumpulkan materi audio visual berupa foto, gambar dan suara yang berasal dari orang yang menginang dan budayawan. Analisis data akan secara langsung bersamaan dengan bagian-bagian lain dari pengembangan penelitian ini, yaitu pengumpulan data dan penulisan temuan. Dalam penelitian ini ditemukan jika kebiasaan ini masih digunakan oleh sebagian masyarakat Melayu Palembang yang bergender perempuan hal ini dikarenakan munculnya stigma masyarakat terhadap kaum laki-laki terhadap kebiasaan nginang yang hanya diidentikan dengan rokok. Kebiasaan nginang mulai menghilang karena adanya faktor keluarga, kemajuan zaman, lingkungan dan lembaga masyarakat.
\end{abstract}

Kata Kunci: Masyarakat Melayu, Nginang, Palembang

\begin{abstract}
The progress of the times and the ease with which foreign cultures enter the life of the current generation have made a lot of local wisdom begin to experience degradation to the point of extinction. As is the case, the younger generation of Palembang Malay descent, at this time has left a tradition that has been passed down from generation to generation, namely the nginang tradition. Nginang is a habit that has become a hereditary tradition carried out by the Malay community in Sumatra and Palembang. This study aims to reveal the phenomenon of the habit of nginang which is still carried out by some Malay people in Palembang. This research uses descriptive-qualitative research using ethnographic method which is an approach to anthropology disciplines. Sources of data used are primary data sources and secondary sources. Primary sources that come from people who nginang and cultural. Secondary sources come from research reports, books, archives, and so on. The data collection technique used direct observation to the location, namely in Seberang Ulu I District, Palembang City. As for using participant interviews, namely key informants as the main data and using relevant literature studies to support this research as well as collecting audio-visual materials in the form of photos, images and sounds that come from the betel nut and cultural observers. Data
\end{abstract}

\footnotetext{
${ }^{1}$ Mahasiswa Prodi SPI UIN Raden Fatah Palembang

${ }^{2}$ Dosen Prodi Sejarah Peradaban Islam, UIN Raden Fatah Palembang

${ }^{3}$ Dosen Prodi Sejarah Peradaban Islam, UIN Raden Fatah Palembang
} 
analysis will be directly in conjunction with other parts of the development of this research, namely data collection and writing of findings. In this study, it was found that this habit is still used by some of the Palembang Malay community who are female, this is due to the emergence of public stigma against men against the habit of nginang which is only identified with cigarettes. The habit of nutmeg is starting to disappear due to family factors, the progress of the times, the environment and community institutions.

Keywords: Malay Society, Nginang, Palembang

\section{A. PENDAHULUAN}

Indonesia adalah negara pluralisme, yang memiliki beragam budaya dan tradisi di dalamnya. Secara etnografis, Indonesia memiliki beragam etnis bermukim di wilayah ini. Etnis itu tersebar di berbagai kepulauan-kepulauan di dalam kawasan yang bernama Negara Kesatuan Republik Indonesia (NKRI). Menurut Kusumohamidjojo, Indonesia merupakan negara multikultural terbesar di dunia dengan dapat dilihat dari sosio kultural hingga geografis Indonesia yang begitu kompleks, beragam dan luas. Selain itu, Masyarakat Indonesia adalah heterogen dengan aneka ragam macam suku bangsa, bahasa, agama, adat-istiadat, dan lainnya. ${ }^{4}$

Keberagaman budaya dan adat-istiadat inilah yang menjadi kekayaan bangsa Indonesia. Seperti halnya, tradisi-tradisi yang pada saat ini masih ada di masyarakat. Menurut KBBI tradisi adalah sebuah adat kebiasaan yang diwariskan secara turun temurun dari leluhur hingga generasi selanjutnya, serta masih dijalankan dalam masyarakat. Sama halnya dengan tradisi nginang. Nginang adalah sebuah kebiasaan mengunyah sirih dan ramuan lainnya seperti kapur, gambir, pinang dan tembakau, yang kemudian diwariskan secara turun temurun dari generasi terdahulu hingga sekarang. Kata Nginang berasal dari Jawa dan berasal dari suku kata pekinangan yang berarti wadah. $^{5}$

Secara historis, kebiasaan menginang sudah lama dikenal dan dipraktikan oleh suku bangsa Melayu. Dalam pengertiannya Melayu berasal dari suku kata mula yang mengandung arti mula atau awal dan kata $y u$ yang mengandung arti negeri. Dengan demikian, Melayu mengandung arti negeri yang mula-mula atau yang awal-awal. Menurut Ellya Roza, Melayu adalah kesatuan masyarakat pribumi yang mendiami wilayah Kepulauan Melayu, atau Alam Melayu yang hidupnya berasal dari merantau dan memiliki wilayah kebudayaan yang disebut Malay Archipelago. Secara geografis, para ahli memiliki asumsi yang berbeda seperti halnya, Menurut Hamka negeri Melayu bermula dari Semenanjung Malaysia lalu ke Sumatera, Jawa, Kalimantan, Sulawesi, dan Pulau-pulau Nusa Tenggara serta pulau-pulau Malaka termasuk Irian dan terus ke Pulau Luzon dan Mindanao. Selain itu, dalam asumsi lain bahwa yang dikategorikan etnis Melayu adalah menggunakan bahasa Melayu dalam bertutur dan berinteraksi. Sedangkan menurut Aziz Deraman, bahwa geografis Kepulauan Melayu meliputi Malaysia, Indonesia, Filipina, Singapura, dan mencangkup seluruh pulau yang terdapat di Asia Tenggara yaitu termasuk sebagian Selatan China, Yunan, Burma, Malagasi, Formosa, Selatan Siam, Kamboja, Vietnam dan Laos. ${ }^{6}$ Secara kesimpulan yang dapat penulis tarik, bahwa pengertian Melayu merupakan suku bangsa yang menggunakan tutur bahasa Melayu dengan geografis hampir mencangkup wilayah Asia Tenggara.

Sebelum kedatangan Islam di tanah Melayu, masyarakatnya menganut agama kepercayaan dari animisme. dinamisme hingga hindu dan budha. Namun, dengan seiring kedatangan Islam di tanah Melayu, secara bertahap masyarakatnya menganut agama Islam. Bahkan Islam sudah

\footnotetext{
${ }^{4}$ Gina Lestari, "Bhinneka Tunggal Ika: Khasanah Multikultural Indonesia Di Tengah Kehidupan Sara," Jurnal Pendidikan Pancasila dan Kewarganegaraan 28, no. 1 (2015): hlm. 31.

${ }^{5}$ Departemen Pendidikan dan Kebudayaan Daerah Jakarta, Peralatan Hiburan Dan Kesenian Tradisional Daerah Sumatera Selatan (Jakarta: Departemen Pendidikan dan Kebudayaan Daerah Jakarta, 1987), hlm. 28.

${ }^{6}$ Ellya Roza, Sejarah Tamadun Melayu (Yogyakarta: Aswaja Pressindo, 2016), hlm. 14-16.
} 
menjadi sebuah panduan dalam hidup, ada sebuah pernyataan jika seorang Melayu ialah beragama Islan, yang berbahasa Melayu sehari-hari dan yang beradat Melayu, serta mengaku diirnya sebagai orang Melayu. ${ }^{7}$

Jika kita lihat dari uraian data di atas, secara geografis Palembang merupakan daerah yang terletak di Pulau Sumatera termasuk ke dalam Kepulauan Melayu dan memiliki kebudayaan Melayu, yang saat ini masih ada dan dipraktikan oleh masyarakatnya. Adapun menurut BPS Kota Palembang tahun 2020 mayoritas masyarakat Palembang adalah beragama Islam.

Secara historis, menurut Anthony Reid, tradisi nginang sudah mulai dilakukan masyarakat Melayu di Asia Tenggara sejak abad 15 Masehi. Nginang dilakukan pada upacara adat seperti ritus dan kehidupan sosial. Dengan demikian, nginang merupakan kebiasaan yang sudah lama dipraktikan ke dalam hidup masyarakat Melayu. Masyarakat yang nginang beranggapan jika dengan mengunyah siriih maka akan terasa kesejukan hati dan dapat menahan rasa lapar dan haus. Selain itu, nginang dapat memberikan keharuman nafas dan dapat menenangkan perasaan serta dapat menyembuhkan penyakit. ${ }^{8}$

Menurut catatan sejarah dari William Marsden, bahwa budaya nginang di Sumatera sudah ada sejak abad ke-18 Masehi. Dengan dibuktikan masyarakat yang mendiami Sumatera menggunakan sirih dan ramuan nginang dalam penyambutan tamu di berbagai acara serta sirih disuguhkan dengan wadah atau tepak yang dibagi dalam status sosialnya. ${ }^{9}$

Berdasarkan data dari J.I. Van Sevenhoven penggunaan sirih dalam tradisi nginang di Palembang sudah ada sejak awal abad 19 M. Hal ini dengan dibuktikan ketika sultan dari Kesultanan Palembang menggunakan tepak sirih sebagai kebutuhan dan dibawa berpergian dengan menggunakan pancalang serta dijaga para pelayan-pelayanannya. ${ }^{10}$

Namun, seiring waktu tradisi nginang mulai meredup dan ditinggalkan oleh orang Melayu Palembang. Hal ini melibatkan banyak faktor yang menjadi penyebabnya budaya nginang tidak lagi populer dan dipraktikan oleh masyarakat Melayu Palembang. Walaupun begitu, masih ada beberapa orang yang masih menginang, karena disebabkan rasa candu dan sulit untuk dilepaskan. Orang yang menginang sendiri dapat digolongkan oleh gender perempuan dengan usia lanjut.

Dalam hal ini, penulis bertujuan untuk mengkaji nginang di masyarakat Melayu Palembang untuk mengungkap kebiasaan nginang dan manfaat dari menginang. Dalam permasalahan yang terjadi apa yang menyebab tradisi ini berubah menjadi kebiasaan yang semakin ditinggalkan.

\section{B. TINJAUAN PUSTAKA}

Dalam penelitian ini, membutuhkan literatur yang memiliki kemiripan objek yang dikaji, namun tidak untuk disamakan dalam segi pembahasannya. Dalam konteks tinjauan pustaka, perlu adanya meninjau kajian objek yang sama untuk melihat dari sisi mana yang perlu dibahas dan tidak perlu dibahas. Hal ini dikarenakan, agar tidak terjadinya plagiat dan dapat merugikan pihak-pihak lainnya. Oleh karena itu, penulis sudah menganalisis penelitian terdahulu sebagai berikut:

Pertama, Penelitian dari Perdana dalam artikel berjudul "Nginang pada Perempuan Jawa di Desa Bandung Baru Kecamatan Adiluwih Kabupaten Pringsewu", pada tahun 2018. Kajian ini menyimpulkan bahwa nginang di Desa Bandung Baru masih ada dan menyimpan berbagai aspek penting bagi kehidupan. Hal inilah yang membuat nginang masih bertahan karena menganduk

\footnotetext{
${ }^{7}$ Husni Thamrin, Antropologi Melayu (Yogyakarta: Kalimedia berjasama dengan Fakultas Ushuluddin UIN Suska Raiu, 2018), hlm. 10,

${ }^{8}$ Anthony Reid, Asia Tenggara Dalam Kurun Niaga 1450-1680 Jilid 1: Tanah Di Bawah Angin, Terj Mochtar Pabotingi (Jakarta: Yayasan Pustaka Obor Indonesia, 2014), hlm. 50-51.

${ }^{9}$ William Marsden, Sejarah Sumatra (The History of Sumatra) Terj: Sutrisno (Yogyakarta: Indolestari, 2016), hlm. 178.

${ }^{10}$ J.I Van Sevenhoven, Lukisan Tentang Ibu Kota Palembang (Yogyakarta: Ombak, 2015), hlm. 9.
} 
aspek sosial dan kesehatan yang masih tetap dipraktikan oleh Perempuan Jawa di Desa Bandung Baru. ${ }^{11}$

Kedua, penelitian oleh Devira Natasya Purba dalam Skripsi, "Fungsi dan Makna Sirih pada Upacara Masyarakat Melayu di Desa Pulau Simardan Kecamatan Datuk Bandar Timur Kabupaten Tanjung Balai”, pada tahun 2019, kajian ini menyimpulkan bahwa sirih selalu menjadi bagian terpenting dalam tata cara perkawinan masyarakat Melayu di daerah tersebut, sirih dan tepak sirih merupakan pelambangan dari tanda penghormatan dalam penyambutan pada upacara perkawinan etnis adat Melayu ${ }^{12}$ dan sirih dipercayai masyarakat setempat, untuk pengobatan tradisional dalam menangani pelbagai penyakit seperti mimisan, sariawan, digigit serangga, gatal-gatal dan lainnya.

Ketiga, Penelitian dari Arief Dwinanto dkk, dalam artikel berjudul "Budaya Sirih Pinang dan Peluang Pelestariannya di Sumba Barat, Indonesia, pada tahun 2019. Kajian ini menyimpulkan bahwa sirih pinang adalah simbol kearifan lokal bagi orang Sumba. Budaya sirih pinang hadir dalam keseharian hidup orang Sumba dari acara formal dan informal hingga ritual adat. Adapun, sirih pinang memiliki beragam fungsi seperti sosial, budaya dan kesehatan. ${ }^{13}$

Berdasarkan hasil tinjauan penelitian di atas sejauh ini masih sulit ditemukan perihal nginang sudah mulai meredup yang menyebabkan orang yang menginang sudah mulai punah. Namun, sejatinya banyak ditemukan kajian nginang ataupun penggunaan sirih dalam kehidupan. Berangkat dari hal inilah peneliti ingin mengkaji kebiasaan nginang dari fungsi dan penyebab nginang di Palembang sudah mulai meredup dan tinggalkan.

\section{METODE PENELITIAN}

Dalam kajian ini menggunakan penelitian bersifat deskriptif kualitatif dengan pendekatan antropologis dan menggunakan sumber data primer dan sekunder. Sumber data primer merupakan data yang berasal dari orang yang menginang, budayawan dan Dinas Kebudayaan Kota Palembang. Sedangkan sumber data sekunder berasal dari penelitian terdahulu dan relevan yaitu dari artikel, jurnal, skripsi dan sebagainya. Teknik pengumpulan data yang digunakan yaitu observasi secara langsung kepada orang yang menginang di Kecamatan Seberang Ulu I. Wawancara yang digunakan adalah wawancara partisipan, sebagaimana informannya adalah orang yang menginang, budayawan dan Staf Dinas Kebudayaan Kota Palembang. Studi pustaka yang digunakan adalah literatur yang relevan serta menggunakan materi audio visual untuk memfoto dan merekam perempuan yang sedang nginang di Kecamatan Seberang Ulu I. Analisis data akan secara langsung bersamaan dengan bagian-bagian lain dari pengembangan penelitian ini, yaitu pengumpulan data dan penulisan temuan.

\footnotetext{
${ }^{11}$ Perdana, "Nginang Pada Perempuan Jawa Di Desa Bandung Baru Kecamatan Adiluwih Kabupaten Pringsewu," Journal of Chemical Information and Modeling (2018): hlm. 7-8.

12 Devira Natasya Purba, "Fungsi Dan Makna Sirih Pada Upacara Masyarakat Melayu Di Desa Pulau Simardan Kecamatan Datuk Bandar Timur Kabupaten Tanjung Balai” (Skripsi S1 Fakultas Ilmu Budaya, Universitas Sumatera Utara, 2019), hlm. 18.

13 Arief Dwinanto, Rini S. Soemarwoto, and Miranda Risang Ayu Palar, "Budaya Sirih Pinang Dan Peluang Pelestariannya Di Sumba Barat, Indonesia,” Patanjala: Jurnal Penelitian Sejarah dan Budaya 11, no. 3 (2019): hlm. 377.
} 


\section{HASIL DAN PEMBAHASAN}

\section{Eksistensi Nginang di Kecamatan Seberang Ulu I}

Secara istilah, nginang merujuk dari kata pakinangan dalam bahasa Jawa yang memiliki arti wadah. ${ }^{14}$ Sedangkan orang Palembang juga mengenal kebiasaan ini dengan sebutan nginang. Nginang adalah sebuah kebiasaan mengunyah sirih dan ramuan dari kapur, gambir, pinang dan tembakau. Kebiasaan ini diwariskan dari generasi ke generasi sehingga kemudian secara berkesinambungan menjadi sebuah tradisi di dalam masyarakat.

Menurut Mr. J.G. Husyer, nginang merupakan perilaku kebiasaan yang memiliki kenikmatan seperti hal dalam menikmati teh, kopi, tembakau dan lainnya. Sedangkan menurut Dr. S. Budhisantoso, dkk, setelah kebiasaan tersebut tumbuhlah fungsi lanjutan seperti simbol dan lambang dari solidaritas dan integrasi dari warga dan masyarakat bagi pendukung kebudayaan tersebut. ${ }^{15}$

Eksistensi nginang di Palembang sendiri sejatinya masih ada dengan bentuk sebuah kebiasaan sehari-hari sebagai pelengkap dalam menemani aktivitas bagi seseorang yang menginang. Nginang sudah menjadi bagian dari kehidupan sebagian masyarakat yang berada di Kecamatan Seberang Ulu I Kota Palembang. Karena masih ada juga yang menggunakan kebiasaan dalam adat istiadat seperti perkawinan adat Palembang dan tarian adat.

Kebiasaan nginang dilakukan secara terus menerus, hingga mengalami kenikmatan dan kenyamanan di dalam diri bagi seseorang yang menginang. Kebiasaan ini sudah lama dilakukan orang Melayu Palembang dan diwariskan secara turun temurun. Kebiasaan yang bermula ditemukan pada zaman kesultanan kemudian masih tetap eksis pada saat ini, walaupun saat ini peminatnya sendiri mulai berkurang. ${ }^{16}$

Latar belakang alasan seseorang menginang, yaitu pada saat ketika menginang maka akan muncul kognisi, sehingga mendapat rasa segar dan tubuh menjadi sehat. Lalu secara berkelanjutan mulai menginang dan kelamaan menikmati dan pada akhirnya kecanduan. Lalu akan mencari sensasi itu kembali. ${ }^{17}$ Adapun, secara khasiat sirih yang dicampuran ramuan nginang memiliki khasiat untuk menyegarkan nafas dan untuk menjaga kesehatan maupun dari penyakit seperti sariawan, sakit gigi, sakit perut dan lainnya. ${ }^{18}$

Dalam hal ini, kecanduan merupakan satu kondisi yang membuat seseorang kehilangan kontrol terhadap suatu hal. Biasanya hal ini merujuk pada perilaku seseorang yang terlalu suka dan didorong oleh keinginan kuat atau kegemaran terhadap satu hal. Seseorang yang mengalami kecanduan biasanya tidak akan memiliki kendali atas apa yang ia lakukan konsumsi atau gunakan. Menurut penuturan Ibu Husna sebagai orang yang menginang, jika ia sudah menjadi kecanduan terhadap sirih dan kebiasaan nginang sudah lama semenjak ia dari gadis. ${ }^{19}$

\footnotetext{
${ }^{14}$ Departemen Pendidikan dan Kebudayaan Daerah Jakarta, Peralatan Hiburan Dan Kesenian Tradisional Daerah Sumatera Selatan, hlm. 28.

${ }^{15}$ Departemen Pendidikan dan Kebudayaan Jakarta, Album Pekinangan Tradisional: Lampung, Kalimantan Selatan, Bali, Sulawesi Utara, Sulawesi Tengah, Nusa Tenggara Timur (Jakarta: Departemen Pendidikan dan Kebudayaan Jakarta, 1991), hlm. 2-3.

${ }^{16}$ Wawancara langsung dengan Vebri Al-Lintani (selaku budayawan ) pada tanggal 9 Maret 2021, pukul 17.00 WIB

${ }^{17}$ Wawancara langsung dengan Vebri Al-Lintani (selaku budayawan ) pada tanggal 9 Maret 2021, pukul 17.00 WIB

${ }^{18}$ Wawancara langsung dengan Eka, selaku Pernah Nginang, pada tanggal 24 Februari 2021, pukul 14.58 WIB

${ }^{19}$ Wawancara langsung dengan Husna, selaku Orang yang Menginang, pada tanggal 27 Februari 2021, pukul 15.06 WIB
} 


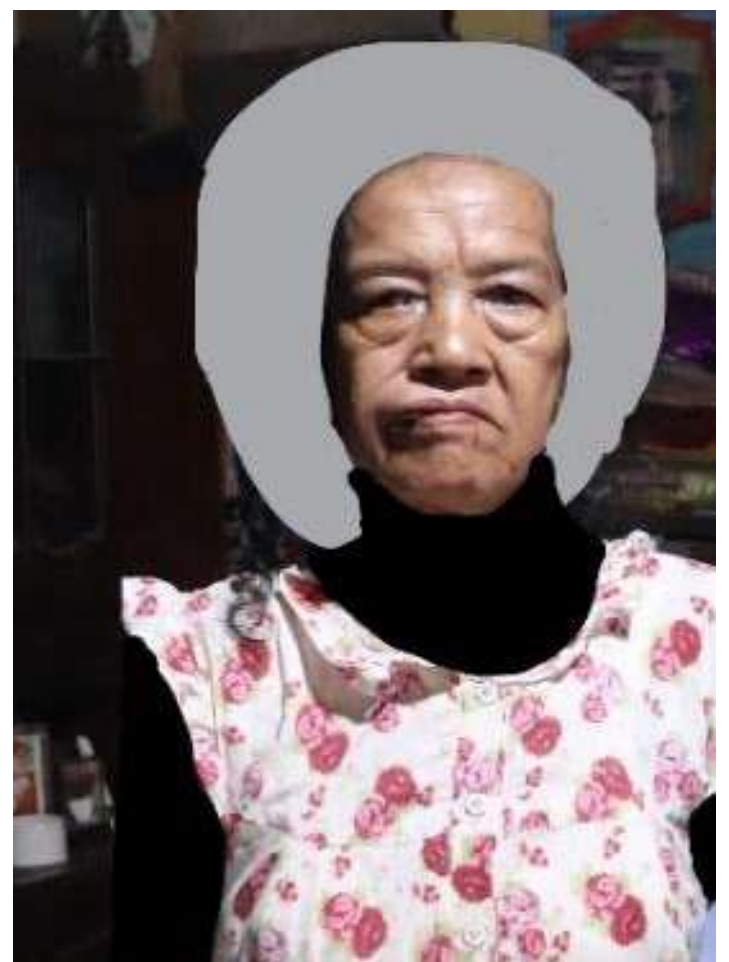

Gambar. 1. Seseorang ibu sedang menginang Sumber: Dokumen Pribadi pada tanggal 27

Sirih yang merupakan tanaman multiguna, sudah menjadi bagian penting dalam kehidupan masyarakat Melayu Palembang. Sebab bagi masyarakat yang menggunakan sirih, akan merasa sirih sebagai benda yang memiliki banyak manfaat dan khasiat yang membantu dalam kehidupan sehari-harinya ${ }^{20}$ Bagi seseorang yang menginang akan berasumsi jika sirih dan ramuan nginang lainnya menjadi barang utama karena jika tidak menginang maka ia merasa dalam dirinya ada yang kurang dan membuat perasaan menjadi tidak enak, seperti analoginya seseorang yang terbiasa merokok akan merasa ada yang asam di mulutnya.

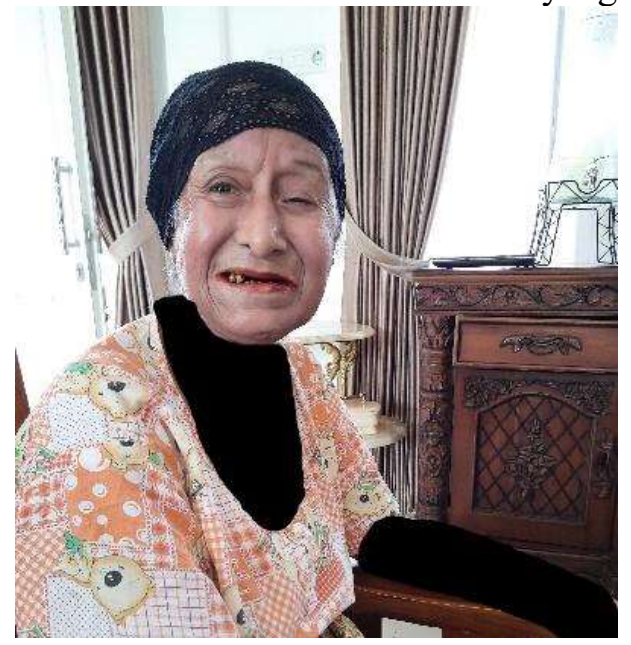

Gambar. 2. Seorang nenek yang sedang asik menginang Sumber: Dokumen Pribadi pada tanggal 28 Februari 2021

\footnotetext{
${ }^{20}$ Wawancara langsung dengan Husna, selaku Orang yang Menginang, pada tanggal 27 Februari 2020, pukul 15.06 WIB
} 
Seseorang yang menginang biasanya melakukan kebiasaan menginang pada saat sesudah makan dan pada saat tidak memiliki kegiatan atau waktu senggang. Biasanya orang yang menginang melakukan kebiasaan nginang 3-4 kali sehari. Pada saat sudah menginang mulut akan terasa segar dan tidak bau. Kebiasaan menginang ini berguna bagi mereka yang memakan santapan yang dapat menimbulkan bau yang kurang sedap. ${ }^{21}$ Seperti memakan jengkol, pete dan makanan yang berpotensi mengganggu orang di sekitarnya.

Dulunya kebiasaan menginang menjadi populer di kalangan masyarakat Melayu di Kecamatan Seberang Ulu I Palembang. ${ }^{22}$ Karena kebiasaan menginang dulunya dilakukan secara kolektif, sekarang menginang dilakukan dengan secara perorangan, karena kebiasaan menginang semakin lama-semakin berkurang. Sehingga sekarang kebiasaan menginang tidak dapat disebut lagi tradisi.

Berdasarkan observasi peneliti, pada saat ini orang yang menginang di Kecamatan Seberang Ulu I didominasi oleh jenis kelamin perempuan berumur. Hal ini disebabkan karena munculnya rokok yang semula para laki-lakinya ikut nginang, kemudian semenjak kemunculan kebiasaan menghisap rokok dan disimbolkan kepada laki-laki, maka semua itu berubah dan tinggalkan budaya nginang. ${ }^{23}$ Belum dapat ditemukan saat ini seseorang yang menginang berjenis kelamin laki-laki di Kecamatan Seberang Ulu I Palembang.

\section{Tata cara meracik ramuan untuk nginang}

Berdasarkan hasil observasi dan wawancara dalam meracik ramuan nginang sebagai berikut:

1) Tahap pertama siapkan bahan-bahannya seperti: Daun Sirih 2 atau 3 lembar, kapur, getah(gambir), pinang (optional) dan tembakau. Daun sirih sebelum digunakan dicuci bersih dan dipilih daun yang segar

2) Selanjutnya, oleskan daun sirih dengan kapur (secukupnya

3) kemudian taburkan gambir dengan di pecahkan menjadi kecil-kecil, lalu lipat daun sirih menjadi dua lipatan.

4) Kemudian, masukan lipatan daun sirih tadi ke dalam mulut, dan selipkan biji pinang (optional) lalu kunyah ramuan tadi hingga berwarna merah, jika sudah ada warna merah air liur tadi bisa dibuang dan makan ramuan tersebut sampai habis.

5) Tahapan akhir, bersihkan gigi dengan sugi atau tembakau dengan mengosok-gosokan tembakau tersebut secara merata dan bersih.

6) Kemudian rasakan kesegaran dan kenikmatan setelah menginang

7) Tertib

\section{Faktor Penyebab Nginang mulai ditinggalkan}

Adapun pada saat ini, budaya nginang mulai menghilang dan hanya dapat ditemukan sebagian masyarakat Melayu di Kecamatan Seberang Ulu I. Berdasarkan hasil observasi dan wawancara penulis menyimpulkan, jika hal ini disebabkan karena ada berbagai faktor yaitu:

\section{a. Faktor Keluarga}

Keluarga merupakan sebuah lembaga atau agen yang bertugas utama mensosialisasikan segala bentuk nilai-nilai kemasyarakatan, keyakinan sikap, pengetahuan, keterampilan dan sains yang akan ditiru oleh penerus selanjutnya. ${ }^{24}$ Dalam hal ini, kurangnya anjuran dari generasi terdahulu kepada generasi sekarang dan kurangnya pemberian informasi secara mendalam dan memberikan keyakinan kepada generasi sekarang untuk

\footnotetext{
${ }^{21}$ Wawancara langsung dengan Noni, selaku Orang yang Menginang, pada tanggal 28 Februari 2020, pukul 12.39 WIB

${ }^{22} \mathrm{Ibid}$.

${ }^{23}$ Wawancara langsung dengan Vebri Al-Lintani, selaku Budayawan Palembang, pada tanggal 9 Maret 2021, pukul 17.00 WIB

${ }^{24}$ Rohmat, "Keluarga Dan Pola Pengasuhan Anak," Studi Gender \& Anak 5, no. 1 (2010): hlm. 2.
} 
melakukan kebiasaan nginang. ${ }^{25}$ Contohnya kurangnya anjuran dari nenek sebagai generasi terdahulu untuk memberikan informasi kepada anak atau cucunya. Betapa pentingnya nginang dalam kehidupan seperti untuk kesehatan dan sebagainya.

\section{b. Faktor arus globalisasi}

Menurut Barker Globalisasi merupakan sebuah keterhubungan dengan berbagai aspek seperti dalam bidang ekonomi, sosial, budaya dan politik, yang nantinya akan mengarah ke berbagai arah di seluruh penjuru dunia dan merasuk ke dalam kesadaran kita. Proses perkembangan globalisasi pada awalnya akan ditandai dengan kemajuan dibidang teknologi informasi dan komunikasi. Dari kemajuan ini akan berdampak dalam mempengaruhi aspek-aspek lain seperti ekonomi, politik, sosial, budaya dan lain-lain. ${ }^{26}$ Dengan kemajuan informasi yang cepat maka arus modernisasi akan meluas ke seluruh dunia, hal ini akan berdampak bagi generasi muda yang meniru budaya asing dan melupakan budayanya dan identitas bangsanya, sehingga termasuklah budaya nginang ini yang pada akhirnya menjadi dilupakan generasi muda dan ditinggalkan. ${ }^{27}$ Seperti munculnya kebiasaan merokok yang lama kelamaan menggantikan budaya nginang pada generasi sekarang.

\section{c. Faktor Lingkungan}

Menurut St. Munajay Danusaputra bahwa Lingkungan merupakan hal yang berkaitan dengan benda dan kondisi yang berhubungan dengan manusia serta aktivitasnya dan termasuk kedalam ruang dimana manusia berada dan mempengaruhi, kelangsungan hidup, kesejahteraan manusia dan jasa hidupnya. ${ }^{28}$

Dalam analoginya fenomena nginang terjadi karena adanya faktor lingkungan, karena disebabkan dari sekitar lingkungan masyarakat yang tidak melestarikan budaya nginang dan ada sebagian masyarakat menganggap nginang merupakan hal yang aneh dan jorok, karena mengeluarkan air liur berwarna merah. ${ }^{29}$ Dengan demikian, akan berdampak pergeseran budaya serta menghilangnya budaya dan ditinggalkan.

\section{d. Faktor Lembaga Masyarakat}

Lembaga merupakan sebuah organisasi yang memiliki tujuan untuk melakukan suatu penyelidikan keilmuan atau melakukan suatu usaha. ${ }^{30}$ Lembaga kemasyarakatan menurut Robert Maclver dan Charles H. Page adalah sebagai sebuah prosedur yang telah diciptakan untuk memberikan aturan kepada manusia dengan manusia yang berkelompok dalam suatu kelompok kemasyarakatan yang dinamakan asosiasi. ${ }^{31}$

Dalam fenomena nginang mulai memudar, karena kurangnya sosialisasi dan informasi dari lembaga-lembaga terkait tentang khasiat dari nginang dan belum ada upaya yang konkret untuk melestarikan budaya nginang. Sebab kurangnya hal tersebut, membuat nginang mulai menghilang dimasyarakat Melayu di Palembang yang salah satunya di wilayah Kecamatan Seberang Ulu I.

\footnotetext{
${ }^{25}$ Wawancara langsung dengan Reza Pahlevi, selaku Praktisi Pengobatan Tradisional, pada tanggal 23 April 2021 , jam 14.00 WIB

${ }^{26}$ B. Suhartini, "Perspektif Global," Majora 53, no. 9 (2007): hlm. 5.

${ }^{27}$ Wawancara langsung dengan Reza Pahlevi, selaku Praktisi Pengobatan Tradisional, pada tanggal 23 April 2021, jam 14.00 WIB

${ }^{28}$ Rita Oktaviani, "Pelestarian Lingkungan Hidup" (2007): hlm. 3.

${ }^{29}$ Wawancara langsung dengan Dr. Nyimas Umi Kalsum, M.Hum, selaku Tim Pembina Adat Provinsi Sumsel, pada tanggal 16 Maret 2021, pukul 11.00 WIB

${ }^{30} \mathrm{https} / / / \mathrm{kbbi}$.web.id/lembaga (diakses dan dikutip pada tanggal 28 April 2021, pukul 19.41 WIB)

${ }^{31}$ Soerjono dan Budi Sulistyowati Soekanto, Sosiologi Suatu Pengantar Edisi Revisi (Jakarta: Rajawali Pers, 2015), hlm. 172.
} 


\section{E. PENUTUP}

Kebiasaan nginang sudah menjadi tradisi di kalangan masyarakat Melayu terutama di Palembang. Kebiasaan ini sudah diwariskan dari generasi ke generasi. Bagi sebagian masyarakat Melayu Palembang kebiasaan ini bermanfaat untuk menjaga penampilan dan memberikan kesegaran dan kesehatan bagi tubuhnya. Selain itu, nginang juga merupakan sebuah manifestasi wujud menghargai warisan dari leluhur mereka.

Namun, seiring waktu nginang yang merupakan tradisi berubah menjadi kebiasaan yang biasa saja dan hanya dinikmati bagi kaum perempuan. Hal ini, dikarenakan munculnya simbol baru yaitu rokok yang mengidentitaskan bahwa kebiasaan itu lebih menyimbolkan kelakian. Sehingga kebiasaan nginang lebih cenderung dipraktikan kaum perempuan.

Lalu seiring zaman pula, kebiasaan menginang sudah mulai dilupakan bahkan nyaris ditinggalkan. Karena ada faktor yang mempengaruhi kebiasaan ini menjadi sebuah kebiasaan yang sudah tidak zaman dan terkesan kuno yaitu terdapat faktor keluarga, dalam faktor keluarga, kurangnya rasa anjuran dari generasi yang masih menginang kepada anak atau cucu untuk melakukan kebiasaan ini serta terdapat faktor kemajuan zaman yang membuat keengganan generasi muda yang cenderung condong meniru kebiasaan luar membuat mereka enggan untuk melakukan kebiasaan tersebut. Lalu terdapat faktor lingkungan yang tidak mendukung membuat kurangnya rasa untuk saling memiliki dan kurangnya rasa keprihatinan dari lembaga yang dapat memberikan sosialisasi sehingga kebiasaan ini menjadi lestari dan tetap terjaga dalam beberapa waktu. 


\section{DAFTAR PUSTAKA}

Departemen Pendidikan dan Kebudayaan Daerah Jakarta. Peralatan Hiburan Dan Kesenian Tradisional Daerah Sumatera Selatan. Jakarta: Departemen Pendidikan dan Kebudayaan Daerah Jakarta, 1987.

Departemen Pendidikan dan Kebudayaan Jakarta. Album Pekinangan Tradisional: Lampung, Kalimantan Selatan, Bali, Sulawesi Utara, Sulawesi Tengah, Nusa Tenggara Timur. Jakarta: Departemen Pendidikan dan Kebudayaan Jakarta, 1991.

Marsden, William. Sejarah Sumatra (The History of Sumatra) Terj: Sutrisno. Yogyakarta: Indolestari, 2016.

Reid, Anthony. Asia Tenggara Dalam Kurun Niaga 1450-1680 Jilid 1 : Tanah Di Bawah Angin, Terj Mochtar Pabotingi. Jakarta: Yayasan Pustaka Obor Indonesia, 2014.

Roza, Ellya. Sejarah Tamadun Melayu. Yogyakarta: Aswaja Pressindo, 2016.

Sevenhoven, J.I Van. Lukisan Tentang Ibu Kota Palembang. Yogyakarta: Ombak, 2015.

Soekanto, Soerjono dan Budi Sulistyowati. Sosiologi Suatu Pengantar Edisi Revisi. Jakarta: Rajawali Pers, 2015.

Thamrin, Husni. Antropologi Melayu. Yogyakarta: Kalimedia berjasama dengan Fakultas Ushuluddin UIN Suska Raiu, 2018.

B. Suhartini. "Perspektif Global." Majora 53, no. 9 (2007).

Rohmat. "Keluarga Dan Pola Pengasuhan Anak." Studi Gender \& Anak 5, no. 1 (2010): 35-46.

Oktaviani, Rita. "Pelestarian Lingkungan Hidup" (2007): 1-15.

Perdana. "Nginang Pada Perempuan Jawa Di Desa Bandung Baru Kecamatan Adiluwih Kabupaten Pringsewu." Journal of Chemical Information and Modeling (2018).

Dwinanto, Arief, Rini S. Soemarwoto, and Miranda Risang Ayu Palar. "Budaya Sirih Pinang Dan Peluang Pelestariannya Di Sumba Barat, Indonesia." Patanjala : Jurnal Penelitian Sejarah dan Budaya 11, no. 3 (2019): 363.

Lestari, Gina. "Bhinneka Tunggal Ika: Khasanah Multikultural Indonesia Di Tengah Kehidupan Sara.” Jurnal Pendidikan Pancasila dan Kewarganegaraan 28, no. 1 (2015): 31-37.

Purba, Devira Natasya. "Fungsi Dan Makna Sirih Pada Upacara Masyarakat Melayu Di Desa Pulau Simardan Kecamatan Datuk Bandar Timur Kabupaten Tanjung Balai." Skripsi S1 Fakultas Ilmu Budaya, Universitas Sumatera Utara, 2019.

Wawancara langsung dengan Vebri Al-Lintani (selaku budayawan) pada tanggal 9 Maret 2021, pukul 17.00 WIB

Wawancara langsung dengan Eka, selaku Pernah Nginang, pada tanggal 24 Februari 2021, pukul $14.58 \mathrm{WIB}$

Wawancara langsung dengan Husna, selaku Orang yang Menginang, pada tanggal 27 Februari 2021, pukul 15.06 WIB

Wawancara langsung dengan Noni, selaku Orang yang Menginang, pada tanggal 28 Februari 2020, pukul 12.39 WIB

Wawancara langsung dengan Dr. Nyimas Umi Kalsum, M.Hum, selaku Tim Pembina Adat Provinsi Sumsel, pada tanggal 16 Maret 2021, pukul 11.00 WIB

Wawancara langsung dengan Reza Pahlevi, selaku Praktisi Pengobatan Tradisional, pada tanggal 23 April 2021, jam 14.00 WIB

https://kbbi.web.id/lembaga (diakses dan dikutip pada tanggal 28 April 2021, pukul 19.41 WIB) 